\title{
IL-10 inhibits retinal pigment epithelium cell proliferation and migration through regulation of VEGF in rhegmatogenous retinal detachment
}

\author{
QUIQING ZHAO ${ }^{1}$, MINGLI JI ${ }^{2}$ and XUEMEI WANG ${ }^{3}$ \\ ${ }^{1}$ Department of Ophthalmology, The Affiliated Hospital of Yan'an University, Yan'an, Shaanxi 716000; \\ ${ }^{2}$ Department of Ophthalmology, The Second Affiliated Hospital of Xi'an Medical University, Xi'an, Shaanxi 710004; \\ ${ }^{3}$ Department of Ophthalmology, The Affiliated Hospital of Shaanxi University of Traditional Chinese Medicine, \\ Xianyang, Shaanxi 712046, P.R. China
}

Received January 9, 2017; Accepted September 26, 2017

DOI: $10.3892 / \mathrm{mmr} .2018 .8787$

\begin{abstract}
Rhegmatogenous retinal detachment (RRD) is a disorder of the eye that affects physical and mental health. Retinal pigment epithelium (RPE) is closely associated with $\mathrm{RRD}$, and it is hypothesized that RPE-secreted inflammatory cytokines may induce early pathological changes of RRD and may participate in RPE proliferation and migration. The present study determined a role for interleukin (IL)-10 as an RPE-secreted immune regulatory factor that contributes to RRD. A rat RRD model was established and RPE cells were isolated and cultivated. RPE cells were randomly divided into four groups, three treated with different concentrations of IL-10 $(100,50$, and $20 \mathrm{mM})$ and one untreated. RPE cell proliferation was evaluated by MTT assay and the activity of caspase- 3 was also measured. RPE cell invasion was determined by Transwell assay. Vascular endothelial growth factor A (VEGF) expression was examined by reverse transcription-quantitative polymerase chain reaction and western blotting; IL-1 and IL-6 levels were measured by ELISA. IL-10 treatment suppressed RPE cell proliferation and migration, promoted caspase-3 activity, inhibited VEGF mRNA and protein expression, and downregulated the secretion of inflammatory cytokines IL-1 and IL-6 in RRD group compared with the untreated Model group. The aforementioned effects of IL-10 became more evident with increasing IL-10 concentration. IL-10 suppressed inflammation, facilitated RPE cell apoptosis and inhibited cell proliferation and migration through the regulation of VEGF expression.
\end{abstract}

Correspondence to: Dr Xuemei Wang, Department of Ophthalmology, The Affiliated Hospital of Shaanxi University of Traditional Chinese Medicine, 2 Weiyang Road, Xianyang, Shaanxi 712046, P.R. China

E-mail: xuemeiwangoo@163.com

Key words: rhegmatogenous retinal detachment, interleukin-10, vascular endothelial growth factor A, inflammation, proliferation, migration

\section{Introduction}

Rhegmatogenous retinal detachment (RRD) refers to the detachment of the retinal neuroepithelial fiber layer from the retinal pigment epithelium (RPE) layer caused by the positioning of the vitreous body underneath the retinal neuroepithelial layer (1-3). The vitreous body may cause retinal tearing and the resulting tension may separate the retina from the RPE $(4,5)$. RRD is a common ophthalmological disease that usually affects middle-aged men with myopia $(6,7)$. RRD prevents the outer retina layer from obtaining nutrition from choroid, which may lead to atrophy of the detached retina and its subsequent degeneration $(8,9)$. Untreated RRD may lead to impairment or loss of vision, and recovery is unlikely (10). The human eye is made up of millions of non-renewable RPE cells organized into a single-cell layer (11).

Following stimulation with human vitreous or fibronectin, RPE cells differentiate and migrate to the vitreous body $(12,13)$. RPE cells proliferate and secrete molecules into the extracellular matrix (ECM), resulting in formation of periretinal membrane with contraction ability, leading to retinal detachment $(14,15)$. Inflammatory cytokines may be involved in ECM function and cell proliferation; therefore, it was hypothesized that inflammatory cytokines affect ECM, induce abnormal proliferation of RPE cells and contribute to the development of RRD $(16,17)$. Interleukin (IL)-10 is a multifunctional negative regulatory factor that is mainly produced by $\mathrm{T}$ helper cells, activated B cells, mononuclear cells and macrophages $(18,19)$. It participates in the regulation of immune, inflammatory and tumor cells and therefore serves a crucial role in transplantation immunity and in a variety of diseases, including autoimmune, infectious and tumors $(20,21)$. However, the role of IL-10 as an $\mathrm{RPE}$-secreted negative immune regulator of RRD remains to be elucidated.

\section{Materials and methods}

Experimental animals and ethical approval. A total of 20 healthy male Wistar rats (age, 2 months; weight, 250 $\pm 20 \mathrm{~g}$ ) were purchased from Shanghai SLAC laboratory Animal Co., 
Ltd. (Shanghai, China) and raised in the experimental animal center in Yan'an University (Yan'an, China) at a temperature of $21 \pm 1^{\circ} \mathrm{C}$ with $50-70 \%$ humidity, $5 \% \mathrm{CO}_{2}$ and a $12 \mathrm{~h}$ day-night cycle. All rats had free access to food and water. The present study was approved by the Ethics Committee of the Affiliated Hospital of Yan'an University.

Materials and reagents. Atropine eye drops (0.1\%), ofloxacin eye drops $(0.3 \%)$ and mydrin-P were supplied by Merck (Merck \& Co., Inc., Whitehouse Station, NJ, USA). Pentobarbital sodium and lidocaine were purchased from Zhpharma (Shanghai Zhonghua Pharmaceutical Co., Ltd., Shanghai, China). IL-10 was purchased from Sigma-Aldrich (Merck KGaA, Darmstadt, Germany). High glucose Dulbecco's modified Eagle medium (DMEM), fetal bovine serum (FBS) and penicillin-streptomycin were obtained from HyClone (GE Healthcare Life Sciences, Logan, UT, USA). Dimethyl sulfoxide (DMSO) and MTT were supplied by Gibco (Thermo Fisher Scientific, Inc., Waltham, MA, USA). Trypsin was obtained from Sigma-Aldrich (Merck KGaA). Polyvinylidene fluoride (PVDF) membrane was purchased from Pall Life Sciences (Port Washington, NY, USA). Western blotting reagents including polyvinylidene fluoride (PVDF) membrane and Tween-20 were obtained from Beyotime Institute of Biotechnology (Shanghai, China). Peroxidase substrate for Enhanced Chemiluminescence (ECL) reagent was purchased from Amersham (GE Healthcare, Chicago, IL, USA). Rabbit anti-rat vascular endothelial growth factor (VEGF) monoclonal antibody (cat. no. 9698) and horseradish peroxidase (HRP)-conjugated immunoglobulin G goat anti-rabbit secondary antibody (cat. no. 7074) were purchased from Cell Signaling Technology, Inc., Danvers, MA, USA). IL-1 $\beta$ (cat. no. RLB00) and IL-6-specific (cat. no. R6000B) ELISA kits were supplied by R\&D Systems, Inc. (Minneapolis, MN, USA). Caspase-3 activity detection kit was purchased from Cell Signaling Technology, Inc. SYBR ${ }^{\circledR}$-Green Quantitative RT-qPCR kit was from Sigma-Aldrich (Merck KGaA, Darmstadt, Germany). A Transwell chamber was purchased from Corning Incorporated (Corning, NY, USA). The microplate reader was purchased from Labsystems Diagnostics Oy (Vantaa, Finland). ABI 7700 Fast Real Time PCR was supplied by Thermo Fisher Scientific, Inc. Benchtop was purchased from Suzhou Purification Engineering Installation Co., Ltd. (Suzhou, China). A Forma incubator was purchased from Thermo Fisher Scientific, Inc.

Rat RRD model establishment. The rat RRD model was established as previously described (22). Briefly, following $0.1 \%$ pentobarbital sodium intraperitoneal anesthesia injection, rats were placed in supine position. Atropine eye drops $(0.1 \%)$ and ofloxacin eye drops $(0.3 \%)$ were administered to rats for 3 days (1 drop daily) prior to the surgery. At the same time, $100 \mu \mathrm{l} 0.5 \%$ Mydrin-P was used to induce mydriasis 3 days prior to surgery. Lidocaine $(2 \%)$ and bupivacaine $(0.75 \%)$ (Sigma-Aldrich, Merck KGaA) were applied subconjunctivally for local anesthesia. Needles (30 gauge) were used to mechanically induce retinal detachment of $\sim 2 \mathrm{~mm}$ under the rim of the right eye on the sclera and retina. Needles were then inserted back into the subretinal space followed by injection of $70 \%$ sodium hyaluronate (Sigma-Aldrich, Merck KGaA) until successful induction of retinal detachment was achieved. A total of 10,000 units of gentamicin and dexamethasone (Sigma-Aldrich, Merck KGaA) were injected locally and chloramphenicol (Sigma-Aldrich, Merck KGaA) eye drops were used postoperatively to prevent infection. Eye examination was performed with an operating microscope to evaluate whether RRD was successfully induced (Fig. 1).

RPE cell culture. Rats were anesthetized with retrobulbar injections of lidocaine (2\%) and the eyeballs were subsequently removed. Rats were subsequently sacrificed using cervical dislocation method. The eyeballs were washed with gentamycin and placed in DMEM. The eyeballs were cut open $3 \mathrm{~mm}$ posterior to the corneoscleral limbus, and the anterior segment and vitreous body were removed and discarded. The remaining tissue was digested with trypsin $(0.25 \%)$ at room temperature for $10 \mathrm{~min}$. The retinal neurepithelium layer was separated, removed and discarded. The retinal neurepithelium tissue was further digested with trypsin $(0.25 \%)$ at $37^{\circ} \mathrm{C}$ for $30 \mathrm{~min}$. The resulting cell suspension was centrifuged at $125 \mathrm{x} \mathrm{g}$ for $10 \mathrm{~min}$ at room temperature and cells (purity $>90 \%$ ) were cultured in DMEM medium containing $100 \mathrm{U} / \mathrm{ml}$ penicillin and $100 \mu \mathrm{g} / \mathrm{ml}$ streptomycin at $37^{\circ} \mathrm{C}$. RPE cells in the 2nd-8th generation and logarithmic phase were used in subsequent experiments. Cells were randomly divided into four groups: One untreated Model group and three IL-10 groups, which received different concentrations of IL-10 (100, 50 , and $20 \mathrm{mM}$ ) for $48 \mathrm{~h}$ at room temperature.

MTT assay. RPE cells in logarithmic phase were seeded onto a 96-well plate at a density of $5 \times 10^{3}$ cells/well and cultured for $24 \mathrm{~h}$ at $37^{\circ} \mathrm{C}$. The cells were divided into the four aforementioned groups and treated accordingly. Following $48 \mathrm{~h}$ of culture, MTT $(20 \mu \mathrm{l})$ was added to each well and incubated for $4 \mathrm{~h}$ at $37^{\circ} \mathrm{C}$. Subsequently, DMSO (150 $\mu \mathrm{l} /$ well $)$ was added to the plate, which was then shaken for $10 \mathrm{~min}$. The absorbance value was measured at a wavelength of $570 \mathrm{~nm}$. Each experiment was run in triplicate.

ELISA. A total of $5 \times 10^{3} \mathrm{RPE}$ cells in logarithmic phase were collected followed by centrifugation at $500 \mathrm{x} g$ for $10 \mathrm{~min}$ at room temperature to obtain the supernatant which was used to measure IL-1 $\beta$ and IL- 6 levels by ELISA kits according to manufacturer's instructions. A total of $50 \mu \mathrm{l}$ diluted standard solution was added to the 96-well plate to obtain the standard curve. A total of $50 \mu \mathrm{l}$ supernatant sample was added to each well. Following washing five times using PBS, conjugate reagent $(50 \mu \mathrm{l} /$ well) was added to the wells and incubated at $37^{\circ} \mathrm{C}$ for $30 \mathrm{~min}$. Subsequently, reagent A (50 $\left.\mu \mathrm{l} / \mathrm{well}\right)$ and reagent $\mathrm{B}(50 \mu \mathrm{l} /$ well $)$ were added and the plate was incubated at $37^{\circ} \mathrm{C}$ for $10 \mathrm{~min}$. The stop buffer $(50 \mu \mathrm{l} /$ well) was added and the absorbance value was measured at a wavelength of $450 \mathrm{~nm}$. The linear regression equation of standard curve was calculated relative to the concentration of the standard substance. The sample concentration was determined from the absorbance value.

Caspase-3 activity detection. RPE cells $\left(5 \times 10^{3} / \mathrm{ml}\right)$ were digested with trypsin and centrifuged at $600 \mathrm{x} \mathrm{g}$ and $4^{\circ} \mathrm{C}$ for 5 min. Subsequently, lysis buffer was added into PRE cells 


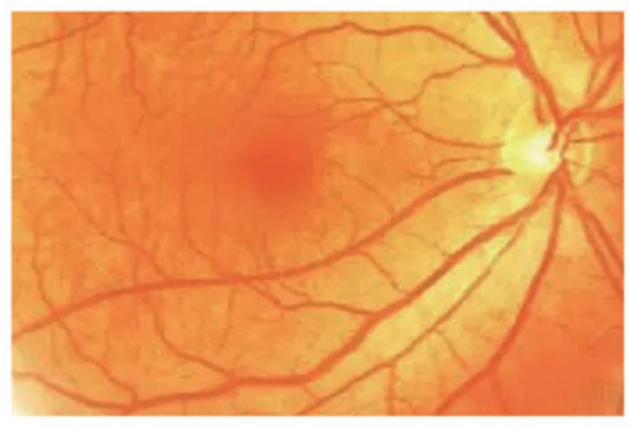

Control

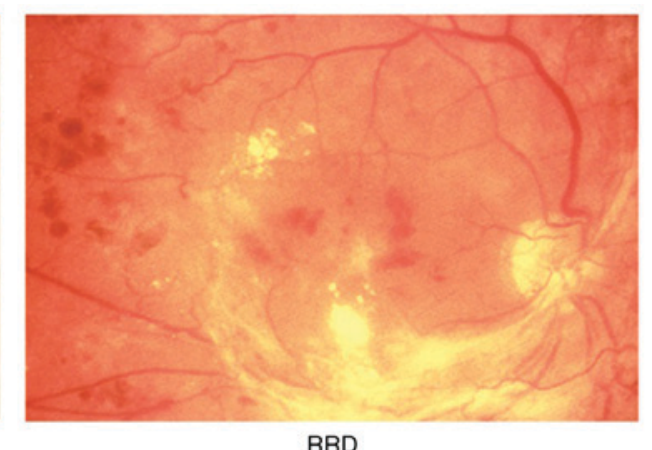

RRD

Figure 1. Changes in the fundus of the eye of a rat from the control group or the experimentally induced rhegmatogenous retinal detachment group (magnification, x40). Model group displayed interruption in retinal neurepithelium layer, apophysis and detachment on RPE, and opaque dark area of fluid. RPE, retinal pigment epithelium; control, model group without interleukin-10 treatment.

and incubated on ice for $15 \mathrm{~min}$. Following centrifugation $\left(20,000 \mathrm{x} \mathrm{g} ; 4^{\circ} \mathrm{C} ; 5 \mathrm{~min}\right), 2 \mathrm{mM}$ Ac-DEVD-pNA (Santa Cruz Biotechnology, Inc., Dallas, TX, USA) was added to the suspension and the absorbance value was measured at a wavelength of $405 \mathrm{~nm}$.

Reverse transcription-quantitative polymerase chain reaction (RT-qPCR). Total RNA was extracted from RPE cells $\left(5 \times 10^{3} / \mathrm{ml}\right)$ using TRIzol (Thermo Fisher Scientific, Inc.); and reverse transcribed to cDNA using $\mathrm{SYBR}^{\circledR}$-Green Quantitative RT-qPCR kit (Sigma-Aldrich; Merck KGaA) according to manufacturer's protocol. Primers were designed using Primer Premier software version 6.0 (Premier Biosoft International, Palo Alto, CA, USA) and synthetized by Invitrogen (Thermo Fisher Scientific, Inc.); primer sequences are presented in Table I. qPCR reactions were performed at $95^{\circ} \mathrm{C}$ for $1 \mathrm{~min}$, followed by 35 cycles at $92^{\circ} \mathrm{C}$ for $30 \mathrm{sec}, 58^{\circ} \mathrm{C}$ for $45 \mathrm{sec}$, and $72^{\circ} \mathrm{C}$ for $35 \mathrm{sec}$. GAPDH was selected as an internal reference gene. The relative expression level was calculated using the $2^{-\Delta \Delta \mathrm{Cq}}$ method (23) and represented as a fold changes relative to GAPDH.

Western blotting. Total protein was extracted from RPE cells $\left(5 \times 10^{3} / \mathrm{ml}\right)$ on ice using the radioimmunoprecipitation assay buffer for 15-30 min. Following ultrasonications 4 times at $37^{\circ} \mathrm{C}, 5 \mathrm{sec}$ each, and centrifugation at $4^{\circ} \mathrm{C}$ and $10,000 \mathrm{x} \mathrm{g}$ for $15 \mathrm{~min}$, the protein solution was transferred to a new Eppendorf tube. $\mathrm{RPE}$ proteins were stored at $-20^{\circ} \mathrm{C}$ following quantification using Pierce BCA Protein Assay kit (Thermo Fisher Scientific, Inc.). Proteins were loaded into $10 \%$ SDS-PAGE $(20 \mu \mathrm{g} / \mathrm{well})$ at $100 \mathrm{~mA}$ for $1.5 \mathrm{~h}$ and transferred to a PVDF membrane. Following blocking with 5\% skim milk at room temperature for $2 \mathrm{~h}$, the membrane was incubated with primary antibodies against VEGF $(1: 1,000)$ and $\beta$-actin $(1: 2,000)$ at $4^{\circ} \mathrm{C}$ overnight. The membrane was washed with PBS with $0.05 \%$ Tween-20 and further incubated with HRP-conjugated goat anti-rabbit secondary antibody at 1:2,000 for $30 \mathrm{~min}$ at room temperature. Protein bands were visualized with ECL reagent for $1 \mathrm{~min}$ and developed. $\beta$-actin used as a loading control and to normalize expression in densitometric analysis. The membrane was scanned with an image processing system and analyzed using Quantity One 1-D Analysis Software version 4.6.5 (Bio-Rad Laboratories, Inc., Hercules, CA, USA). Each experiment was repeated four times.
Table I. Primer sequences for reverse transcription-quantitative polymerase chain reaction.

\begin{tabular}{ll}
\hline Gene & \multicolumn{1}{c}{ Primer sequence $\left(5^{\prime} \rightarrow 3^{\prime}\right)$} \\
\hline GAPDH & F: ACCAGGTATCTTGGTTG \\
& R: TAACCATGTCAGCGTGGT \\
VEGF & F: AGGTCTAACAGTCTCGCCAC \\
& R: TCATTAGCGTAGCCATCTAACC
\end{tabular}

F, forward; R, reverse; VEGF, vascular endothelial growth factor.

Cell migration assay. RPE cell suspensions were collected at the logarithmic phase (density of cells, $5 \times 10^{3} / \mathrm{ml}$ ) under $12 \mathrm{~h}$ starvation culture in cell starvation medium (Sigma-Aldrich; Merck KGaA) following treatments with different concentrations of IL-10 and subsequently added into upper part of the Transwell chamber containing DMEM medium. 10\% FBS was added into the lower part of the chamber. Following incubation at $37^{\circ} \mathrm{C}$ for $24 \mathrm{~h}$, cells in the upper membrane were removed using a pipette tip or cotton tipped applicator and RPE cells were stained with $0.1 \%$ crystal violet at room temperature for $10 \mathrm{~min}$ and observed under an inverted microscope. Five fields were selected for each staining and cell numbers were counted.

Statistical analysis. SPSS software (version 19.0; IBM Corp., Armonk, NY, USA) was used for data analysis. All data were presented as the mean \pm standard deviation. Intergroup differences were analyzed by analysis of variance. $\mathrm{P}<0.05$ was considered to indicate a statistically significant difference.

\section{Results}

Effects of IL-10 on RPE cell proliferation in RRD. Eye examination was performed with an operating microscope to demonstrate the interruption in retinal neurepithelium layer, apophysis and detachment of RPE, and opaque dark area of fluid, suggesting that RRD was successfully induced (Fig. 1). An MTT assay was used to evaluate the effects of IL-10 on RPE cell proliferation in RRD. All three concentrations of IL-10 (20, 50 and $100 \mu \mathrm{M})$ significantly inhibited RPE cell proliferation compared with the untreated Model group 


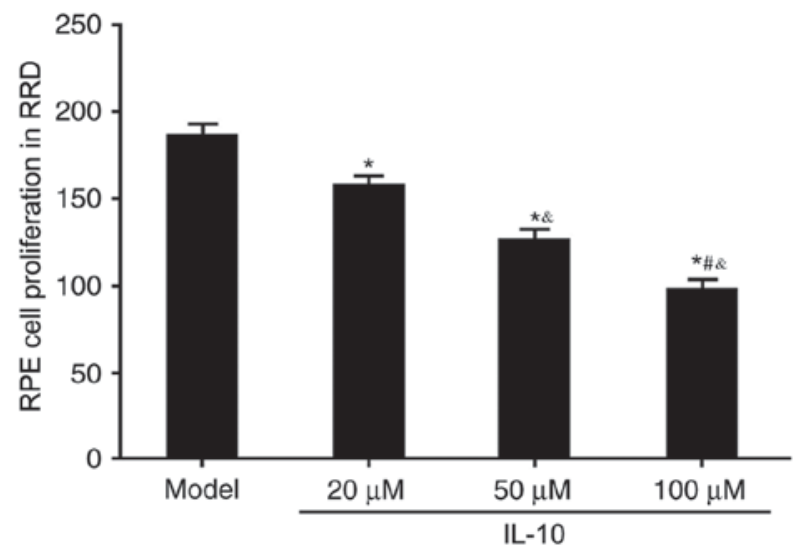

Figure 2. Effects of IL-10 treatment on RPE cell proliferation in RRD model rats. RPE cells were isolated from RRD rat and cultured in vitro followed by addition of different concentrations of IL-10. The effect of IL-10 on cell proliferation was measured by MTT assay. ${ }^{*} \mathrm{P}<0.05$ vs. Model group; ${ }^{\circledR} \mathrm{P}<0.05$ vs. $20 \mathrm{mM}$ IL-10 group; ${ }^{\# P}<0.05$ vs. $20 \mathrm{mM}$ IL-10 group. IL, interleukin; $\mathrm{RRD}$, rhegmatogenous retinal detachment; RPE, retinal pigment epithelium.

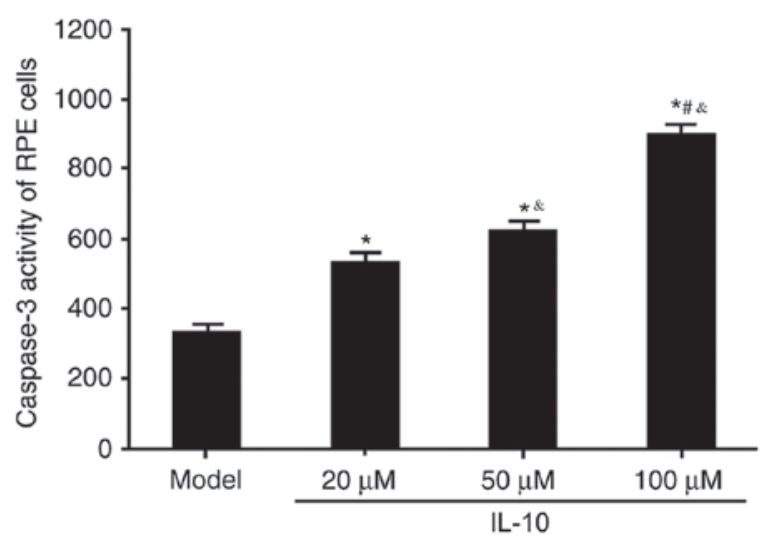

Figure 3. Effects of IL-10 on caspase-3 activity in RPE cells from rhegmatogenous retinal detachment model rats. RPE cells were isolated from RRD rat and treated with addition of different concentrations of IL-10 followed by measuring caspase-3 activity. ${ }^{*} \mathrm{P}<0.05$ vs. model group; ${ }^{\circledR} \mathrm{P}<0.05$ vs. $20 \mathrm{mM}$ IL-10 group; "P<0.05 vs. 20 mM IL-10. IL, interleukin; RPE, retinal pigment epithelium; RRD, rhegmatogenous retinal detachment.

$(\mathrm{P}<0.05$; Fig. 2); this inhibitory effect on cell proliferation appeared to be in a dose-dependent manner.

Effects of IL-10 on caspase-3 activity in RPE cells from RRD model rats. Caspase-3 activity was measured to evaluate the effects of varying concentrations of IL-10 on apoptotic activity in RPE cells from RRD. IL-10 treatment significantly increased caspase- 3 activity compared with the Model group $(\mathrm{P}<0.05$; Fig. 3), and this effect was in a dose-dependent manner. These results indicated that IL-10 may facilitate RPE cell apoptosis, which may subsequently serve an inhibitory role on RRD progression.

Effects of IL-10 on inflammatory cytokine expressions in $R P E$ cells from RRD model rats. ELISA was used to measure the abundance of inflammatory cytokines IL-1 $\beta$ and IL-6 in the supernatant of RPE cells from RRD. IL-10 treatments significantly suppressed expression of IL-1 $\beta$ and IL-6 in RPE cells derived from RRD ( $\mathrm{P}<0.05$ vs. Model; Fig. 4), and this

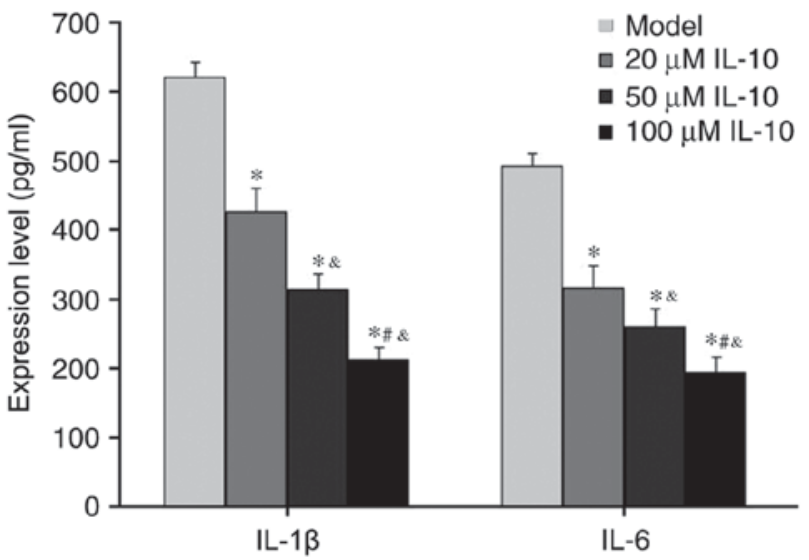

Figure 4. Effects of IL-10 on inflammatory cytokine expression levels in retinal pigment epithelial cells from rhegmatogenous retinal detachment model rats. Cell supernatant was collected from cells after treated with IL-10 for measuring IL- $1 \beta$ and IL- 6 by ELISA. ${ }^{*} \mathrm{P}<0.05$ vs. Model group; ${ }^{\circledR} \mathrm{P}<0.05$ vs. $20 \mathrm{mM}$ IL-10 group; ${ }^{\#} \mathrm{P}<0.05$ vs. $20 \mathrm{mM}$ IL-10. IL, interleukin.

reduction was dose-dependent. These results suggested that IL-10 inhibited inflammatory cytokine secretion from RPE.

Effects of IL-10 on RPE cell migration in RRD. The Transwell assay was used to determine the effects of IL-10 on RPE cell migration in RRD. IL-10 expression significantly restrained RPE migration in RRD compared with the untreated model group $(\mathrm{P}<0.05)$, and the effect was dose dependent (Fig. 5A and $\mathrm{B})$. These results suggested that IL-10 may regulate RPE cell migration in RRD.

Effects of IL-10 on VEGF mRNA and protein expression in $R P E$ from RRD model rats. RT-qPCR and western blotting were used to analyze the effects of different concentrations of IL-10 on VEGF mRNA and protein expression in RPE cells from RRD. It was demonstrated that the IL-10 treatments significantly downregulated VEGF mRNA and protein expressions in RPE cells from RRD in a dose-dependent manner, compared with untreated Model cells ( $\mathrm{P}<0.05$; Fig. 6).

\section{Discussion}

RPE cells migrate to the vitreous body, promote secretion of a large amount of inflammatory cytokines and facilitate the secretion of ECM, ultimately leading to ECM reconstruction and the development of retinal detachment $(24,25)$. RRD is an inflammatory pathological process, in which a tear forms on the lower surface of retina or at the interface between the vitreous body and the retina, and leads to further secretion of inflammatory cytokines, including IL-1 $\beta$ and IL-6. The tear promotes ECM secretion to form a pathological deposition, which pulls on the retina and causes retinal detachment (26). The risk factors of retinal detachment include genetic factors, aging, reduction of immune capacity and abnormal hyperplasia of RPE cells (27). Elevated secretion of inflammatory cytokines IL-1 $\beta$ and IL-6 leads to inflammation and induces abnormal growth and migration of RPE cells (28). Inflammation in RPE cells serves a role in the development and pathogenesis of RRD; however, whether IL-10, an anti-inflammatory cytokine, serves a role in RRD remains to be elucidated. The present 
A
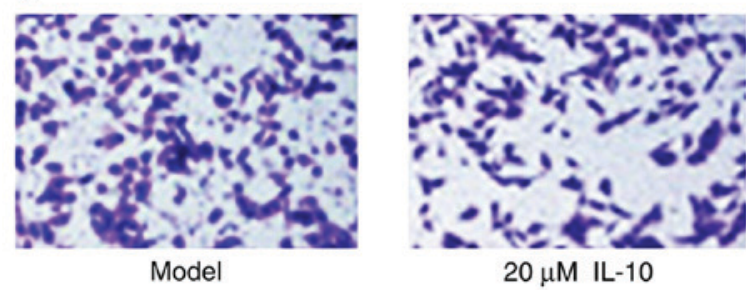

$20 \mu \mathrm{M} \mathrm{IL}-10$

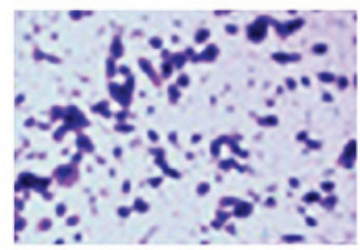

$50 \mu \mathrm{M}$ IL-10

B

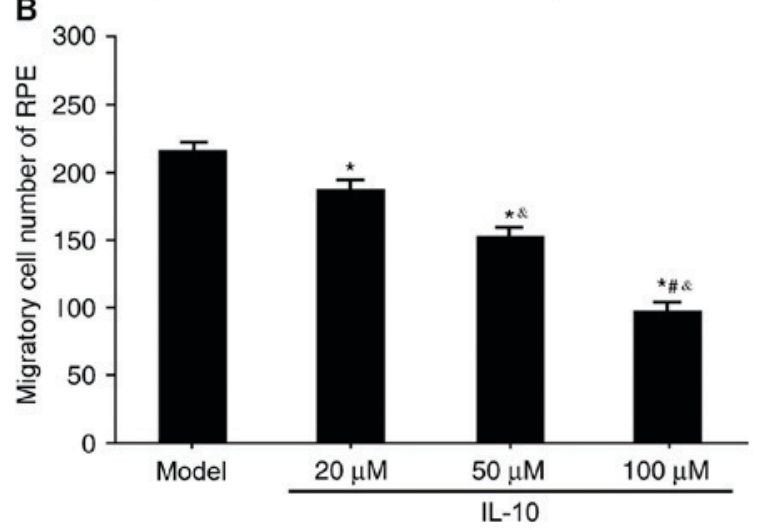

Figure 5. Effects of IL-10 on retinal pigment epithelial cell migration in rhegmatogenous retinal detachment model rats in the untreated Model group and in the 20,50 and $100 \mathrm{mM}$ IL-10-treated groups (magnification, x40). IL, interleukin. (A) Representative graph showing cell migration. (B) Quantified data of cell migration. ${ }^{*} \mathrm{P}<0.05$ vs. the Model group; ${ }^{\circledR} \mathrm{P}<0.05$ vs. $20 \mathrm{mM}$ IL-10 group; ${ }^{*} \mathrm{P}<0.05$ vs. the $20 \mathrm{mM}$ IL-10. IL, interleukin; RPE, retinal pigment epithelium.

study demonstrated that IL-10 treatment inhibited proliferation and migration of RPE cells from RRD model rats.

IL-10 was first described as a T helper 2-derived cytokine; however, it is now considered that IL-10 may not be restricted to a $\mathrm{T}$ cell subset, but instead is produced by most leukocytes (29). The immunosuppressive activity of IL-10 is mediated by heterodimeric IL-10 receptors IL-10R 1 and IL-10R2 (30,31). A previous study demonstrated that human IL-10 inhibits the secretion of interferon (IFN)- $\gamma$ in peripheral blood mononuclear cells (32), and in the presence of accessory cells, IL-10 inhibits mitogen or anti-CD3 monoclonal antibody-stimulated $\mathrm{T}$ cell proliferation (33). It has been also demonstrated that IL-10-mediated inhibition of T cell growth was associated with decreased production of IFN- $\gamma$ and IL-2 (33). Consistent with the role of IL-10 as an inhibitor of cell proliferation, the present study demonstrated that IL-10 treatment significantly inhibited RPE cell proliferation and migration in a dose-dependent manner. Furthermore, treatment of RPE cells with IL-10 also reduced the secretion of pro-inflammatory cytokines IL-1 $\beta$ and-6.

The angiogenic factor VEGF is expressed in vascular endothelial cells, nerve cells and retinal cells; it binds to transmembrane tyrosine kinase VEGF receptors on the plasma membrane, which induces receptor dimerization
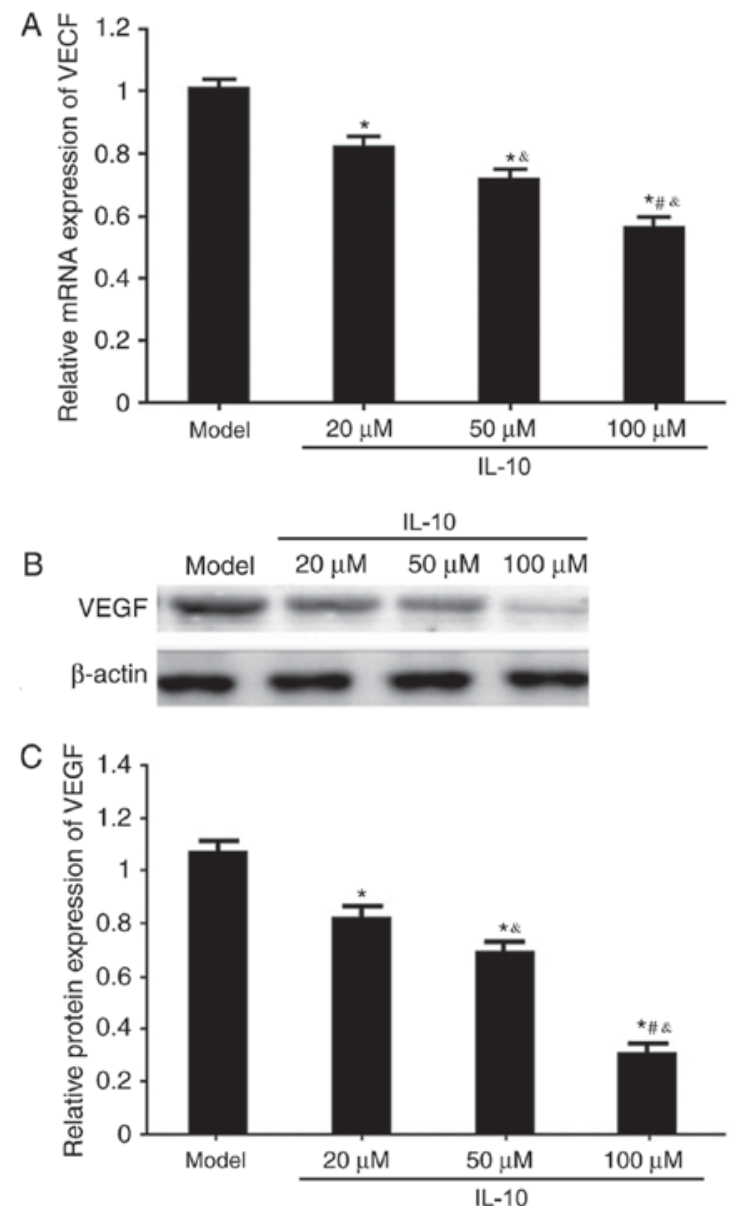

Figure 6. Effects of IL-10 on VEGF mRNA and protein expressions in RPE from RRD. (A) Reverse transcription-quantitative polymerase chain reaction detection of VEGF mRNA expression in the Model and IL-10 treatment groups. (B) Western blotting of VEGF protein expression in the Model and IL-10 treatment groups. (C) Densitometric analysis of the effects of IL-10 treatment on VEGF protein expression in RPE cells from RRD in (B). ${ }^{*} \mathrm{P}<0.05$ vs. Model group; ${ }^{\&} \mathrm{P}<0.05$ vs. $20 \mathrm{mM}$ IL-10 group; ${ }^{\#} \mathrm{P}<0.05$ vs. $20 \mathrm{mM}$ IL-10. IL, interleukin; RPE, retinal pigment epithelium; RRD, rhegmatogenous retinal detachment; VEGF, vascular endothelial growth factor.

and activation, and the assembly of a membrane-proximal signaling complex (34). VEGF may promote cell proliferation, differentiation, migration and movement by increasing the permeability of blood vessels and degradation of extracellular matrix (35). VEGF upregulation may promote blood vessel growth, facilitate inflammatory factors secretion and aggravate inflammation, leading to damage of vascular integrity (36). In the present study, a significant reduction in the expression levels of VEGF mRNA and protein in RPE cells was observed following IL-10 treatment, which suggested that IL-10 may inhibit angiogenesis through the downregulation of VEGF expression. These results are consistent with a previous study, which demonstrated that mice with a VEGF-producing ovarian cancer exhibited an IL-10-mediated inhibition of angiogenesis and tumor growth (37). However, the exact mechanisms underlying the IL-10-mediated regulation of VEGF expression in RPE cells remain to be elucidated.

In conclusion, IL-10 may suppress inflammation, facilitate RPE cell apoptosis and limit cell proliferation and migration by regulating VEGF expression to delay RRD progression. 


\section{References}

1. Nemet A, Moshiri A, Yiu G, Loewenstein A and Moisseiev E: A review of innovations in rhegmatogenous retinal detachment surgical techniques. J Ophthalmol 2017: 4310643, 2017.

2. Ghazi NG and Green WR: Pathology and pathogenesis of retinal detachment. Eye (Lond) 16: 411-421, 2002.

3. Kang HK and Luff AJ: Management of retinal detachment: A guide for non-ophthalmologists. BMJ 336: 1235-1240, 2008.

4. Huang C, Zhang T, Liu J, Ji Q and Tan R: Changes in axial length, central cornea thickness and anterior chamber depth after rhegmatogenous retinal detachment repair. BMC Ophthalmol 16: 121, 2016.

5. Yumusak E, Ornek K and Ozkal F: Bilateral simultaneous rhegmatogenous retinal detachment following laser in situ keratomileusis. Case Rep Ophthalmol 7: 341-345, 2016.

6. Kominami A, Ueno S, Kominami T, Nakanishi A,Piao CH, Ra E, Yasuda S, Asami T and Terasaki H: Restoration of cone interdigitation zone associated with improvement of focal macular ERG after fovea-off rhegmatogenous retinal reattachment. Invest Ophthalmol Vis Sci 57: 1604-1611, 2016.

7. Gotzaridis S, Liazos E, Petrou P and Georgalas I: 25-Gauge vitrectomy and incomplete drainage of subretinal fluid for the treatment of primary rhegmatogenous retinal detachment. Ophthalmic Surg Lasers Imaging Retina 47: 333-335, 2016.

8. Takahashi E, Fukushima A, Haga A, Inomata Y, Ito Y, Fukushima $\mathrm{M}$ and Tanihara $\mathrm{H}$ : Effects of mechanical stress and vitreous samples in retinal pigment epithelial cells. Biochem Biophys Res Commun 470: 569-574, 2016.

9. Heriot WJ: Thermofusion of the retina with the RPE to seal tears during retinal detachment repair. Graefes Arch Clin Exp Ophthalmol 254: 691-696, 2016.

10. Sukseree S, Chen YT,Laggner M,GruberF,Petit V,Nagelreiter IM, Mlitz V, Rossiter H, Pollreisz A, Schmidt-Erfurth U, et al: Tyrosinase-Cre-mediated deletion of the autophagy gene atg7 leads to accumulation of the RPE65 Variant M450 in the retinal pigment epithelium of C57BL/6 mice. PLoS One 11: e0161640, 2016.

11. Koutsandrea C, Kanakis M, Papaconstantinou D, Brouzas D, Ladas I, Petrou P and Georgalas I: Scleral buckling versus vitrectomy for retinal detachment repair: Comparison of visual fields and nerve fiber layer thickness. Ophthalmologica 235: 10-17, 2016.

12. Hinton DR, He S, Graf K, Yang D, Hsueh WA, Ryan SJ and Law RE: Mitogen-activated protein kinase activation mediates PDGF-directed migration of RPE cells. Exp Cell Res 239: 11-15, 1998.

13. Kirchhof B, Kirchhof E, Ryan SJ and Sorgente N: Vitreous modulation of migration and proliferation of retinal pigment epithelial cells in vitro. Invest Ophthalmol Vis Sci 30: 1951-1957, 1989.

14. Knickelbein JE, Liu B, Arakelyan A, Zicari S, Hannes S, Chen P, Li Z, Grivel JC, Chaigne-Delalande B, Sen HN, et al: Modulation of immune responses by extracellular vesicles from retinal pigment epithelium. Invest Ophthalmol Vis Sci 57: 4101-4107, 2016.

15. Mones J, Leiva M, Peña T, Martínez G, Biarnés M, Garcia M, Serrano A and Fernandez E: A swine model of selective geographic atrophy of outer retinal layers mimicking atrophic AMD: A phase $i$ escalating dose of subretinal sodium iodate. Invest Ophthalmol Vis Sci 57: 3974-3983, 2016.

16. Fields MA, Cai H, Bowrey HE, Moreira EF, Beck Gooz M, Kunchithapautham K, Gong J, Vought E and Del Priore LV: Nitrite modification of extracellular matrix alters CD46 expression and VEGF release in human retinal pigment epithelium. Invest Ophthalmol Vis Sci 56: 4231-4238, 2015.

17. Shaw PX, Stiles T, Douglas C, Ho D, Fan W, Du H and Xiao X: Oxidative stress, innate immunity and age-related macular degeneration. AIMS Mol Sci 3: 196-221, 2016.

18. Fernandez-Godino R, Pierce EA and Garland DL: Extracellular matrix alterations and deposit formation in AMD. Adv Exp Med Biol 854: 53-58, 2016.

19. Yamawaki T, Ito E, Mukai A, Ueno M, Yamada J, Sotozono C, Kinoshita $\mathrm{S}$ and Hamuro J: The ingenious interactions between macrophages and functionally plastic retinal pigment epithelium cells. Invest Ophthalmol Vis Sci 57: 5945-5953, 2016.
20. Tenconi PE, Giusto NM, Salvador GA and Mateos MV: Phospholipase D1 modulates protein kinase C-epsilon in retinal pigment epithelium cells during inflammatory response. Int J Biochem Cell Biol 81: 67-75, 2016.

21. Du H, Xiao X, Stiles T, Douglas C, Ho D and Shaw PX: Novel mechanistic interplay between products of oxidative stress and components of the complement system in AMD pathogenesis. Open J Ophthalmol 6: 43-50, 2016.

22. Zhang RF, Liu ZR, Chen B and Zhang JJ: The impact of miR-26b on retinal pigment epithelium cells in rhegmatogenous retinal detachment model. Int J Clin Exp Patho 10: 8141-8147, 2017.

23. Livak KJ and Schmittgen TD: Analysis of relative gene expression data using real-time quantitative PCR and the 2(-Delta Delta C(T)) method. Methods 25: 402-408, 2001.

24. Dardik R, Livnat T, Halpert G, Jawad S, Nisgav Y, Azar-Avivi S, Liu B, Nussenblatt RB, Weinberger D and Sredni B: The small tellurium-based compound SAS suppresses inflammation in human retinal pigment epithelium. Mol Vis 22: 548-562, 2016.

25. Fu D, Yu JY, Connell AR, Yang S, Hookham MB, McLeese R and Lyons TJ: Beneficial effects of berberine on oxidized LDL-induced cytotoxicity to human retinal muller cells. Invest Ophthalmol Vis Sci 57: 3369-3379, 2016.

26. Sreekantam S, Macdonald T, Keane PA, Sim DA, Murray PI and Denniston AK: Quantitative analysis of vitreous inflammation using optical coherence tomography in patients receiving sub-Tenon's triamcinolone acetonide for uveitic cystoid macular oedema. Br J Ophthalmol 101: 175-179, 2017.

27. Estrago-Franco MF, Moustafa MT, Riazi-Esfahani M, Sapkal AU, Piche-Lopez R, Patil AJ, Sharma A, Falatoonzadeh P, Chwa M, Luczy-Bachman G, et al: Effects of benzo(e)pyrene on reactive oxygen/nitrogen species and inflammatory cytokines induction in human RPE cells and attenuation by mitochondrial-involved mechanism. J Ophthalmic Vis Res 11: 385-393, 2016.

28. Keir LS, Firth R, Aponik L, Feitelberg D, Sakimoto S, Aguilar E, Welsh GI, Richards A, Usui Y, Satchell SC, et al: VEGF regulates local inhibitory complement proteins in the eye and kidney. J Clin Invest 127: 199-214, 2017.

29. Kuhn R, Löhler J, Rennick D, Rajewsky K and Müller W: Interleukin-10-deficient mice develop chronic enterocolitis. Cell 75: 263-274, 1993.

30. Walter MR: The molecular basis of IL-10 function: From receptor structure to the onset of signaling. Curr Top Microbiol Immunol 380: 191-212, 2014.

31. Mosser DM and Zhang X: Interleukin-10: New perspectives on an old cytokine. Immunol Rev 226: 205-218, 2008.

32. Naundorf S, Schroder M, Hoflich C, Suman N, Volk HD and Grutz G: IL-10 interferes directly with TCR-induced IFN-gamma but not IL-17 production in memory T cells. Eur J Immunol 39: 1066-1077, 2009

33. Taga K and Tosato G: IL-10 inhibits human T cell proliferation and IL-2 production. J Immunol 148: 1143-1148, 1992.

34. Sen P, Vinay Kumar S, Bhende M and Sharma T: Combined argon laser photocoagulation and antivascular endothelial growth factor for management of macular polypoidal choroidal vasculopathy. Oman J Ophthalmol 9: 139-143, 2016.

35. Corydon TJ, Mann V, Slumstrup L, Kopp S, Sahana J, Askou AL, Magnusson NE, Echegoyen D, Bek T, Sundaresan A, et al: Reduced expression of cytoskeletal and extracellular matrix genes in human adult retinal pigment epithelium cells exposed to simulated microgravity. Cell Physiol Biochem 40: 1-17, 2016.

36. Kim SH, Kim H, Ku HJ, Park JH, Cha H, Lee S, Lee JH and Park JW: Oxalomalate reduces expression and secretion of vascular endothelial growth factor in the retinal pigment epithelium and inhibits angiogenesis: Implications for age-related macular degeneration. Redox Biol 10: 211-220, 2016.

37. Kohno T, Mizukami H, Suzuki M, Saga Y, Takei Y, Shimpo M, Matsushita T,Okada T, Hanazono Y, Kume A, et al: Interleukin-10mediated inhibition of angiogenesis and tumor growth in mice bearing VEGF-producing ovarian cancer. Cancer Res 63: 5091-5094, 2003. 